\title{
GESTÃO ESCOLAR DEMOCRÁTICA: ENTRE O PROMULGADO E A PRÁTICA
}

\author{
GESTIÓN ESCOLAR DEMOCRÁTICA: ENTRE PROMULGAR Y PRACTICAR \\ DEMOCRATIC SCHOOL MANAGEMENT: BETWEEN PROMULGATED AND \\ PRACTICE
}

Sidmar da Silva OLIVEIRA ${ }^{1}$

\begin{abstract}
RESUMO: O objetivo desta pesquisa é compreender os elementos dificultadores e os caminhos possíveis para efetivação da gestão escolar democrática em Monte Santo-BA. Trata-se de um estudo netnográfico, de abordagem qualitativa, que parte da seguinte questão: quais os elementos dificultadores e os caminhos possíveis para efetivação da gestão escolar democrática em Monte Santo-BA? Para atingir o objetivo proposto e responder à questão central, realizou-se uma entrevista semiestruturada com três profissionais da educação que atuaram na direção de escolas por indicação política e por processo eletivo, e traçou-se uma discussão das aspirações e crenças dos sujeitos com os estudos teóricos sobre gestão escolar democrática e proposições impressas nos diplomas legais. Os resultados apontam que a eleição para gestores escolares é um mecanismo fundamental para promoção da gestão escolar democrática que dialoga com os anseios dos interlocutores da pesquisa, mas ainda depende da vontade política dos governantes locais para ser efetivada.
\end{abstract}

PALAVRAS-CHAVE: Gestão escolar democrática. Participação. Autonomia.

RESUMEN: El objetivo de esta investigación es comprender los elementos que lo dificultan y los posibles caminos para una gestión escolar democrática efectiva en Monte Santo-BA. Se trata de un estudio netnográfico, con enfoque cualitativo, que parte de la siguiente pregunta: ¿cuáles son los elementos que obstaculizan y los posibles caminos para la efectividad de la gestión escolar democrática en Monte Santo-BA? Para lograr el objetivo propuesto y dar respuesta a la pregunta central, se realizó una entrevista semiestructurada con tres profesionales de la educación que trabajaron en la dirección de escuelas por indicación política y por proceso electivo y una discusión de las aspiraciones y creencias de los sujetos con los estúdios teóricos sobre la gestión escolar democrática y proposiciones impresas en los diplomas legales. Los resultados muestran que la elección de administradores escolares es un mecanismo fundamental para promover la gestión escolar democrática y que dialoga con los deseos de los interlocutores de investigación, pero aún depende de la voluntad política del gobierno local que se lleve a cabo.

PALABRAS CLAVE: Gestión escolar democrática. Participación. Autonomía.

${ }^{1}$ Secretaria Municipal de Educação (SME), Monte Santo - BA - Brasil. Professor da Educação Básica. Membro do Grupo de Pesquisa intitulado Grupo de Estudo e Pesquisa em (Multi)letramentos, Educação e Tecnologias (GEPLET). Mestrado Profissional em Educação e Diversidade (UNEB). ORCID: https://orcid.org/0000-00024914-6647. E-mail: sydy.oliveira10@gmail.com 
ABSTRACT: The objective of this research is to understand the elements that make it difficult and the possible paths for effective democratic school management in Monte Santo-BA. This is a nethnographic study, with a qualitative approach, which starts from the following question: what are the elements that hinder and the possible ways for effective democratic school management in Monte Santo-BA? To achieve the proposed objective and answer the central question, a semi-structured interview was conducted with three education professionals who worked in the direction of schools by political indication and by elective process and a discussion of the subjects' aspirations and beliefs with the studies theorists about democratic school management and propositions printed in the legal diplomas. The results show that the election for school administrators is a fundamental mechanism for promoting democratic school management and that dialogues with the desires of the research interlocutors, but it still depends on the political will of the local government to be carried out

KEYWORDS: Democratic school management. Participation. Autonomy.

\section{Introdução: a pesquisa, o objeto e os objetivos}

As mudanças socioculturais e tecnológicas que permeiam a sociedade exigem que a escola reconfigure seus modos de atuação. Este processo demanda uma gestão escolar democrática capaz de descentralizar o poder e fomentar a participação efetiva de todos os atores da comunidade nas decisões administrativas, pedagógicas e financeiras. Na prática, a participação é um princípio da democracia que potencializa a transparência e se constitui como "[...] principal meio de assegurar a gestão democrática da escola, possibilitando o envolvimento de profissionais e usuários no processo de tomada de decisões e no funcionamento da organização escolar" (LIBÂNEO, 2004, p. 102).

Neste ínterim, a gestão democrática é um tema sempre atual nos programas e políticas educacionais do país. Em escritos e discursos concernentes à educação, é nítido que autonomia, participação e democracia são princípios que precisam se consumar na escola; mas, consolidar esses preceitos e democratizar a educação exige remover das escolas os obstáculos políticos, de governo e de gestão, de teorias e de objetivos que interferem na constituição de organizações educativas democráticas (LIMA, 2018).

Frente às discussões situadas sobre a gestão democrática, este estudo objetiva compreender os elementos dificultadores e os caminhos possíveis para efetivação da gestão escolar democrática em Monte Santo-BA. A pesquisa está alicerçada no método netnográfico, aqui entendido como forma adaptada da etnografia para estudar realidades e sujeitos em ambientes digitais, fóruns de discussão, videoconferências, blogs e redes sociais (KOZINETS, 2014). A netnografia não trata as comunicações on-line apenas como conteúdos ou formas, mas como artefatos culturais embebidos de significados.

RPGE- Revista on line de Política e Gestão Educacional, Araraquara, v. 25, n. 3, p. 2147-2162, set./dez. 2021. e-ISSN: 1519-9029 
Por se desenvolver em uma situação natural, possuir um plano flexível e focalizar a realidade situada (LÜDKE; ANDRÉ, 1986), a abordagem qualitativa foi escolhida para condução da pesquisa. No devir do estudo qualitativo, a história pessoal e as posições políticas do pesquisador são pontos de partida para investigação, artifícios que dialogam com uma pesquisa que busca construir um conhecimento provisório para responder à seguinte questão-problema: quais os elementos dificultadores e os caminhos possíveis para efetivação da gestão escolar democrática em Monte Santo-BA?

Para alcançar o objetivo proposto e responder à provocação central, realizou-se uma entrevista semiestruturada, em janeiro de 2021, organizada em um questionário por meio do Google Forms ${ }^{2}$, com três profissionais ${ }^{3}$ da educação que já atuaram na direção de escolas por processo eletivo e por indicação política. A entrevista foi escolhida por propiciar a obtenção de dados referentes aos diversos aspectos da vida social (GIL, 2008) e por oportunizar aos sujeitos a expressarem seus conhecimentos, aspirações, expectativas e crenças sobre a gestão escolar democrática no cotidiano municipal.

O corpus para reflexão e discussão teórica foi construído a partir da unitarização e categorização (MORAES, 2003) do material produzido, movimento que propiciou a seleção das respostas relevantes para este estudo que se justifica pela necessidade de estudar a gestão democrática e problematizar seu ordenamento jurídico, urgência de discutir a concepção dos atores educacionais acerca dos métodos de escolha de diretores e importância de conceber a eleição direta como um mecanismo da gestão democrática, visando refletir sobre outras modalidades de escolha de gestores escolares ${ }^{4}$.

A relevância acadêmica deste estudo deriva da urgência de problematizar o princípio da gestão democrática implícito e explícito nos diplomas legais, que exigem novas proposições do poder público e da sociedade, as quais dialoguem com as práticas de gestão escolar democrática necessária ao contexto atual. É socialmente relevante por promover discussões situadas sobre o movimento de escolha para dirigentes escolares praticadas no município, bem como por suscitar proposições que dialogam com a gestão escolar democrática na forma da lei.

\section{Gestão escolar democrática em Monte Santo-BA: do texto ao contexto}

\footnotetext{
${ }^{2}$ Serviço gratuito da Google para criar formulários on-line, pesquisas, avaliações etc.

${ }^{3}$ Os termos de cessão de direitos autorais foram assinados por todos os participantes da pesquisa, e para manter suas identidades sob sigilo, refere-se a eles pelos seguintes pseudônimos: Assis, Ayla e Júlia.

${ }^{4}$ Neste estudo, os substantivos diretor e gestor são utilizados com sinônimos. Ademais, a opção pelo uso do masculino se justifica porque a voz do pesquisador está implícita na escrita, mas às questões relativas a gênero são reconhecidas e respeitadas no itinerário da escrita.
} 
A gestão escolar democrática presume a participação ativa de todos os atores da comunidade nas decisões administrativas, pedagógicas e financeiras. A concepção de escola democrática ganhou destaque com a redemocratização do país, quando foram institucionalizadas as aspirações de intelectuais e de idealistas políticos na Constituição Federal (CF) e na Lei de Diretrizes e Bases da Educação Nacional (LDB). Com efeito, a gestão democrática do ensino público passou a ser um dos princípios fundamentais apregoados no Art. 206 da CF e no Art. $3^{\circ}$ da LDB; mas, a efetivação ainda é um desafio a ser discutido, enfrentado e vencido em muitas redes de ensino.

As adversidades que acometem a gestão político-educacional e o distanciamento entre o promulgado e a prática são elementos manifestos na educação pública. Prova disso é que o princípio da gestão democrática, que já deveria estar consolidado, ainda é uma das diretrizes e metas do Plano Nacional de Educação (PNE). De fato, mesmo com o intuito de "assegurar condições, no prazo de dois anos, para a efetivação da gestão democrática da educação, associada a critérios técnicos de mérito e desempenho e à consulta pública à comunidade escolar [...]” (BRASIL, 2014, p. 83), o princípio da gestão democrática tem provocado múltiplas discussões e interpretações.

Em Monte Santo-BA, locus deste estudo, a gestão democrática da educação pública é um pilar da Lei Orgânica do Município de Monte Santo que, em seu Art. 66, parágrafo único, preconiza que "Os diretores e Vice-Diretores serão escolhidos através de eleições diretas na forma da lei" (MONTE SANTO, 2012, p. 39), e do Estatuto do Magistério Público do Município de Monte Santo, Lei no 16/2013, que em seu Art. 67 define que "A direção de unidade de ensino do município será exercida pelo Diretor e pelo Vice-Diretor, escolhidos mediante eleição, de forma democrática e harmônica com o Conselho Escolar" (MONTE SANTO, 2013, p. 27).

Na mesma direção, o Plano Municipal de Educação (PME), especificamente na meta 18, visa "assegurar condições, no prazo de quatro meses (4), para a efetivação da gestão democrática da educação, associada a critérios técnicos de mérito e desempenho e à consulta pública à comunidade escolar [...]" (MONTE SANTO, 2015, p. 108), e o Plano de Cargos e Salários, Lei $n^{0}$ 001/2016, que define, no Art. 14, que “A escolha das funções gratificadas de Diretor e Vice-diretor recairá em profissionais da educação integrantes do quadro efetivo do Magistério Público Municipal, eleitos em pleito direto pela Comunidade Escolar [...]” (MONTE SANTO, 2016, p. 12-13). Diante disso, a eleição direta, nos termos dos diplomas legais do município é o método de escolha dos diretores e vice-diretores das escolas públicas do município. 
Amparando-se nos dispositivos legais supracitados, a Secretaria Municipal de Educação de Monte Santo-BA realizou, em dezembro de 2015, a primeira eleição para gestores escolares nas 33 escolas que possuíam mais de 120 alunos. Mesmo admitindo que a eleição para diretores seja apenas um dos princípios da gestão democrática do ensino público, o pleito eletivo realizado foi um grande passo para efetivar a gestão escolar democrática em Monte Santo-BA; mas, debates e divergências político-administrativas revelaram comutação de leis, ações e discursos, impedindo a realização do segundo pleito eletivo, previsto para dezembro de 2018.

Em meio às divergências político-administrativas e apoiando-se nos diplomas legais pátrios que não dispõem de uma norma clara determinando a eleição de gestores escolares como método de gestão democrática, os poderes executivo e legislativo aprovaram e sancionaram a Lei $n^{0}$ 025/2017, alterando as Leis Municipais $n^{0} 16 / 2013$ e $n^{0} 001 / 2016$ (MONTE SANTO, 2017; 2016). Com a alteração dessas leis, a direção das unidades de ensino do município com mais de 120 alunos não mais seria escolhida por pleito eletivo, mas designados pelo chefe do poder executivo - a conhecida indicação política.

Após vários debates político-administrativos com os profissionais da educação, a governança municipal repensou suas proposições e regulamentou o pleito eletivo por meio do Decreto $n^{\circ} 404 / 2018$ (MONTE SANTO, 2018), provocando debates no meio educacional e ação judicial junto ao Ministério Público (MP) por prevê eleição somente nas 32 escolas que possuíam mais de 120 alunos. Em seu despacho sobre a matéria, o MP advertiu que a legislação municipal é inconstitucional por violar, dentre outros artigos, o Art. $37^{\circ}$, inciso II da Carta Magna. Logo, não teria amparo legal para impugnar o Decreto n ${ }^{\circ} 404 / 2018$ e tampouco para exigir que o executivo implementasse a eleição direta para o provimento do cargo de diretores em todas as unidades escolares do município.

Perante este posicionamento do MP, a gestão municipal decidiu extinguir totalmente a eleição para gestores escolares, provocando curtidas, cutucadas e fissuras para promessas de campanha eleitoral. Passada a eleição municipal de 2020, os poderes legislativo e executivo aprovaram e sancionaram a Lei $n^{0} 088 / 2020$ que introduziu uma nova alteração na Lei $n^{0}$ 16/2013 e redefiniu que a forma de escolha dos diretores e vice-diretores das unidades escolares seria a eleição direta (MONTE SANTO, 2020). Este episódio provocou estranhamento, pois quem outrora foi favorável a extirpar a eleição para diretores mudou o discurso e passou a ser defensor; muitos que eram a favor, passaram a ser contrários, sobretudo, pelos modus operandi ou inversão do poder. 
Sob os preceitos da Lei Municipal $n^{\circ}$ 088/2020, a eleição para diretores teria que ser realizada até 31 de janeiro de 2021; mas, a nova governança municipal alegou que as regras de distanciamento social em decorrência da Covid-19 e o curto período seriam óbices para realizar o pleito eletivo e, por conseguinte, utilizou-se da indicação política para nomear os diretores. Decerto que essas justificativas têm fundamento, mas se caracterizam como estratégica defesa para postergar a efetivação da gestão democrática nas escolas públicas do município.

Para endossar este debate, o legislativo aprovou a Lei $\mathrm{n}^{\circ} 003$, de 15 de fevereiro de 2021, que dispõe sobre a alteração da Lei Municipal n 16/2013 que dispõe sobre o Estatuto do Magistério Público do Município de Monte Santo, alterada pelas Leis n 025/2017 e 088/2020, e dá outras providências (MONTE SANTO, 2021). Neste novo dispositivo, a eleição direta para diretor foi mantida, mas a efetivação da tão comentada gestão democrática segue dependendo de vontade política de quem está no poder, pois o pleito eleitoral para gestores escolares será regulamentado por Ato do Poder Executivo.

\section{Reflexões teórico-práticas: as (inter)faces da gestão escolar democrática}

A escola tem sido espaço de estudos e discussões na atualidade. Dentre os temas em debate, a gestão democrática tem permeado pesquisas e publicações científicas. Para entender a quantidade de estudos sobre o tema e apropriar-se daqueles que dialogam com esta pesquisa, realizou-se uma revisão inicial de literatura, em janeiro de 2021, no SciELO - pesquisas publicadas a partir de 2016 - por se tratar de um recorte temporal atual, tendo gestão escolar democrática como descritor. Os resultados obtidos apontam que há 21 artigos científicos publicados sobre o tema neste período.

Há muitas pesquisas sobre gestão escolar democrática, mas a leitura dos resumos dos artigos apontou três publicações cujos 'achados' dialogam e contribuem para o debate traçado neste texto: Gestão Escolar em Feira de Santana: análise dos textos oficiais; Por que é tão difícil democratizar a gestão da escola pública?; e, Contribuições ao debate sobre gestão democrática da educação: foco em legislações municipais sul-rio-grandenses. A opção pelo diálogo com essas pesquisas se justifica porque ratificam que a eleição de diretores é um mecanismo que contribui para construção da democracia na escola; mas, é uma modalidade que não dispõe de amparo legal no ordenamento jurídico pátrio, ficando a critério ou vontade política dos governantes locais. 
Acresce a essas constatações o fato de que a gestão escolar democrática presume o envolvimento de todos os atores na tomada de decisões da instituição de ensino, o que contribui para descentralizar o poder, democratizar a escola pública e construir uma educação de qualidade social, ou seja, uma educação capaz de dirimir as desigualdades sociais e assegurar a permanência e o sucesso de todos na escola (BRASIL, 2013).

Para Oliveira e Vasques-Menezes (2018, p. 898), “o conceito de gestão escolar é socialmente construído e reconstruído de acordo com a evolução histórica e das políticas educacionais em pauta”. É preciso discutir a gestão escolar democrática no contexto político, sociocultural e econômico, com vistas a atenuar as múltiplas compreensões sobre o tema e construir escolas cuja mudança de concepção, saberes e fazeres acompanhe as transformações da sociedade. Significa dizer que os sistemas de ensino precisam definir as normas da gestão democrática e assegurar às escolas públicas autonomia pedagógica, administrativa e de gestão financeira (BRASIL, 1996).

Um dos desafios da gestão democrática é estabelecer mudanças pessoais e coletivas no cotidiano escolar, pois “[...] nem todos querem edificar mudanças, ou nem todos estão preparados para romper conceitos e práticas estabelecidas, principalmente se tais mudanças não se constituírem em prendas individuais e imediatas" (LIMA, 2013, p. 40). O sucesso da gestão escolar sob o prisma da democracia requer planejamento participativo e descentralização do poder; porém, é preciso extirpar a autocracia, a falsa participação e o amadorismo político-administrativo dos que cuidam da educação.

Em suas ações cotidianas, o diretor "precisa assumir uma postura de articulador da organização do espaço escolar, atuando como sujeito ativo para implementação do direito de aprender e da mobilização e participação social no contexto da escola" (SANTOS; CASTRO, 2020 , p. 12). Este processo exige que o gestor atue como líder, buscando dialogar com toda comunidade escolar para descentralizar o poder e fortalecer os fatores cruciais de uma gestão escolar democrática: autonomia e participação.

A gestão democrática demanda trabalho coletivo, alicerçado nos princípios de autonomia e participação, na perspectiva de promover a aprendizagem e a emancipação humana. Sob este prisma, a gestão escolar democrática implica a participação da comunidade, e a autonomia é condição sine qua non para construção de escolas democráticas e formação de sujeitos críticos-reflexivos e democráticos, capazes de atuar responsivamente na sociedade.

A discussão sobre gestão escolar democrática ganha materialidade ao discutir o tema com quem atua diretamente na direção das escolas. Quando perguntado sobre o que é gestão 
democrática, o professor Assis ${ }^{5}$ informou que é "uma liderança pautada em saber ouvir, questionar e ser questionado; entender que sempre existem outras opiniões, é conviver e saber da importância que tem a participação de todos". Esse excerto discursivo evidencia que a gestão democrática é uma construção coletiva, que demanda gestores comprometidos com o funcionamento administrativo e pedagógico da escola (LIBÂNEO, 2004), e implicados em mobilizar a comunidade para participar da vida institucional da escola e lidar com os múltiplos desafios que permeiam as dimensões da gestão escolar. Trata-se, portanto, de um caminho que se faz ao caminhar, exigindo contínuas reflexões sobre os obstáculos e potencialidades (PARO, 2016) intrínsecas ao processo de construção da gestão escolar democrática da educação pública.

Nesta mesma direção, a professora Júlia afirmou que a gestão democrática é um "processo que envolve a participação efetiva de pais, professores, funcionários e alunos na organização e viabilização dos processos deliberativos". Este extrato discursivo reforça que a gestão escolar democrática só se efetiva se alicerçada no modelo democrático-participativo, no qual as tomadas de decisões acontecem coletivamente (LIBÂNEO, 2004), o que exige superar a perspectiva burocrática das associações de pais e mestres e dos colegiados escolares.

Lima (2013, p. 31) propugna que há cinco quesitos básicos para implementar a gestão escolar democrática: "gostar de participar, querer participar, ter conhecimento do objeto de participação, se reconhecer neste objeto e ter o poder de participação nas tomadas de decisão". Esses aspectos denotam o quão importante é desenvolver ações que fomentem a participação e a autonomia da comunidade escolar.

Estabelecer esse movimento exige compreender que "a gestão escolar é o ato de gerir a dinâmica cultural da escola, afinado com as diretrizes e políticas educacionais públicas para a implementação de seu projeto político-pedagógico" (LÜCK, 2009, p. 24). Para tanto, é vital que toda equipe escolar, sobretudo a direção da escola, tenha espírito de líder democrático, capacidade de dialogar, de construir consensos e coordenar o processo de decisão e realização do trabalho pedagógico, além de equilíbrio e autonomia para construir as pontes necessárias à operacionalização das ações.

O ponto nodal de uma gestão democrática é a socialização e a transparência de informações, processo que demanda participação coletiva, descentralização do poder e autonomia de todos na organização, operacionalização e avaliação das proposições

5 Para preservação da identidade dos professores que colaboraram com este estudo, refere-se a eles por pseudônimos.

RPGE- Revista on line de Política e Gestão Educacional, Araraquara, v. 25, n. 3, p. 2147-2162, set./dez. 2021. e-ISSN: 1519-9029 
administrativas e pedagógicas. Para os interlocutores deste estudo, a efetivação desses princípios é influenciada pela modalidade de escolha do dirigente escolar, posto que,

Quando eleito pela comunidade, somos livres... temos claramente que corresponder com as expectativas da comunidade escolar. Quando indicado, busco também fazer um trabalho que agrade a todos, mas com um detalhe: muitas das vezes submissos permeando no silêncio (Professor Assis).

Eleito: caminha com a comunidade escolar. Indicado: segue hierarquia (Professora Ayla).

Quando é eleito pela comunidade o comprometimento com todos, alunos, funcionários e familiares em participação nas ações e resultados é fundamental na gestão da escola; quando é indicado os interesses partidários se sobrepõem às necessidades e aos desejos da comunidade escolar (Professora Júlia).

Esses depoimentos, aliados aos acontecimentos que perfazem o histórico de escolha dos gestores escolares no município, evidenciam que a eleição é a modalidade de escolha de diretores que potencializa a gestão democrática, mas a democratização das escolas públicas montessantenses ainda depende da vontade política daqueles que estão no poder. Na verdade, a democracia não está restrita apenas às unidades escolares, mas como valor público e sociocultural inerente a todas as esferas sociais, como pilar necessário à formação ética, democrática, crítica e cidadã dos brasileiros.

Ao afirmar que a indicação é uma modalidade que denota seguir hierarquia e que os interesses partidários se sobrepõem às necessidades e aos desejos da comunidade escolar, Ayla e Júlia revelam que a indicação para diretores é uma modalidade que causa danos aos princípios da democracia. Portanto, mesmo que a eleição não seja adotada por questões constitucionais, é preciso superar os obstáculos políticos, entender que a democratização se faz na prática (PARO, 2016) e constituir outros mecanismos de escolha de diretores que comunguem com ideais democráticos.

Quando enfatiza a importância do 'comprometimento de todos', Júlia enfatiza que a escola é uma arena de possibilidades de democratização, espaço privilegiado para diálogo entre todos os atores da comunidade escolar. Entretanto, não se pode negar que a escola é uma arena política e social de participação comunitária, uma instituição de poder e disputa como espaço político-ideológico. Logo, democracia e participação como termos inseparáveis (LÜCK, 2009) precisam ser pilares da gestão escolar.

A importância das organizações participativas nas escolas para a efetivação da gestão democrática é enfatizada pelos colaboradores. Assis afirma que "esses segmentos são as 
testemunhas dos atos. O gestor só segue pelo caminho espinhoso se conivente com os mesmos. Organizados ativos, tornam muito mais democrático todo o processo de liderança". De fato, o colegiado escolar e a associação de pais e mestres possuem funções deliberativas, consultivas e fiscalizadoras, fatores essenciais para democratizar a gestão da escola; porém, só se efetiva quando o poder é descentralizado e existem sujeitos participativos, que atuam nos processos decisórios e contribuem para tornar as instituições democráticas (LIMA, 2013).

Em uma gestão escolar democrática, é fundamental a participação, a autonomia e a responsabilidade individual em prol do coletivo. Para isso, é preciso engajamento da equipe e atuação responsiva do gestor escolar, pois "o diretor escolar é o líder, mentor, coordenador e orientador principal da vida da escola e todo o seu trabalho educacional, não devendo sua responsabilidade ser diluída entre todos os colaboradores da gestão escolar, embora possa ser com eles compartilhada" (LÜCK, 2009, p. 23). Assim, gerir a escola exige conhecimentos e habilidades para exercer liderança e assegurar a participação de todos os segmentos da comunidade escolar nas tomadas de decisões e na solução dos problemas (LIBÂNEO, 2004).

Na concepção de Souza (2009, p. 135), “a participação democrática pressupõe uma ação reguladora, fiscalizadora, avaliadora, além de decisória sobre os rumos da vida política e social das instituições (escolares) e da sociedade”. De certa forma, a participação democrática pode ser principiada com a eleição direta para diretores que, apesar de ser um terreno de disputas de poderes e de mudanças de discursos, os colaboradores defendem o processo eletivo. Assis é favorável à eleição, pois "Devemos ser avaliados pela comunidade escolar. O voto é a ferramenta". Este fragmento revela a importância do processo eletivo e a pertinência da participação e da autonomia como construtos contínuos da gestão escolar democrática.

Na mesma direção, Júlia diz: "Sou a favor da eleição [...]”, e Ayla informa: "Sou a favor, desde que os envolvidos entendam a importância da mesma, pois muitos ainda não compreenderam a real importância da gestão democrática". Destes relatos, é possível inferir que a gestão democrática não pode ser confundida apenas com a eleição direta para provimento de cargo de diretores, mas como processo contínuo que exige autonomia e participação de todos os segmentos da comunidade escolar.

A concepção dos sujeitos deste estudo e os diplomas legais montessantenses comungam com a visão de Paro (2011) quando adverte que a eleição de diretores é o mecanismo mais adequado para o provimento da função, posto que ela impede a dependência política e o clientelismo eleitoral, fortalecendo as relações entre a comunidade escolar e local. Ao facultar independência política aos diretores, o pleito eletivo atende aos princípios de impessoalidade, moralidade e publicidade (BRASIL, 1988); mas, a eleição para gestores nas 
escolas montessantenses ainda é um terreno de disputa de poderes e, como enunciado por Paro (2016), o pleito eletivo não deve acontecer de forma desvinculada de outras medidas que transformem a estrutura administrativa da escola.

Diante das discussões tecidas e da emergência de escolha de gestores escolares que primem pela gestão participativa, democrática e descentralizadora do poder, é vital refletir sobre as formas de escolha de diretores que predominam no Brasil: indicação, eleição, concurso público e esquema misto (ALVES, 2009). A indicação é o mecanismo de provimento do cargo que remete ao poder executivo; a eleição representa o método de escolha da comunidade escolar por meio do voto; o concurso público é um processo seletivo que abrange provas e títulos; e o esquema misto exige aliar experiência profissional, processos técnicos e políticos.

Para efetivação de qualquer modalidade é preciso um olhar multidimensional para suas potencialidades e fragilidades: a indicação, se efetivada com base em critérios técnicos e considerar o perfil educacional dos postulantes ao cargo, poderá atenuar a principal fragilidade - conotação político-partidária; a eleição, que pressupõe maior compromisso do diretor com a comunidade escolar e acredita-se que haja maior engajamento e participação de todos na gestão da escola, pode tornar-se um movimento vicioso do processo políticoeleitoral, como a troca de votos por favorecimento pessoal; o concurso público garante a seleção de candidatos com mais conhecimento teórico e a continuidade no cargo, mas o candidato pode não apresentar um perfil adequado para gerir a escola; e, o esquema misto agrega estratégias que combinam com outras modalidades, com o intuito de minimizar as fragilidades de uma única forma, mas se não conter definições claras e transparência no processo, poderá transformar-se em um mecanismo de pouco interesse dos candidatos e da comunidade escolar.

Seja qual for o método de escolha de gestores, é essencial adotar critérios claros e acompanhar as ações político-educacionais desenvolvidas na escola, com vistas a materializar o princípio da gestão democrática impresso nos diplomas legais pátrios, afinal de contas, na ausência de um conceito claro sobre a gestão democrática, a legislação local incita o debate na direção da rede de ensino encontrar sua própria fórmula de definir e efetivar este princípio (ESQUINSANI, 2016). Para isso, é preciso que o poder público compreenda a importância de suas ações dialogarem com as aspirações da comunidade escolar e que é primordial que seus interesses político-partidários sejam menos influentes nas arenas escolares.

A tessitura teórico-empírica deste estudo revela a importância de a rede de ensino consolidar o processo eletivo para o provimento do cargo de diretores; mas, na ausência desta 
modalidade, é fundante delinear e constituir um esquema misto, no sentido de exigir conhecimento técnico, experiência profissional, apresentação de plano de gestão, entrevistas e adesão a cursos de formação continuada para gestores escolares.

Em meio às decisões judiciais, as mudanças de discurso e o interesse políticoadministrativo, a adoção da eleição direta para diretores e a constituição de novos mecanismos para aperfeiçoar as formas de escolha de gestores parece oportuna em um período marcado por contínuas mudanças sociais, educacionais e tecnológicas, mas é uma questão político-educacional que desafia a governança municipal, os profissionais da educação e a comunidade escolar montessantense.

\section{Considerações finais}

Concebendo a gestão democrática como parte constituinte do currículo escolar e uma das dimensões do processo educativo (LIMA, 2018), os participantes do estudo são unânimes em defender a eleição como modalidade para o provimento do cargo de diretores por garantir maior compromisso do gestor e conceder autonomia pedagógica e administrativa à escola. Efetivar a gestão democrática demanda exaurir os interesses políticos arraigados nas escolas e colocar as reais necessidades e os verdadeiros anseios da comunidade escolar como prioridades.

A análise dos acontecimentos do campo empírico ratifica que a eleição direta por si só não transforma a escola em uma instituição educativa democrática, mas é um potente instrumento para potencializar a gestão democrático-participativa e a formação cidadã. Com efeito, a realidade educacional do locus do estudo denota que a efetivação da gestão escolar democrática não pode ser desejo de alguns, mas uma exigência social calcada na legislação brasileira e no desejo de descentralizar o poder e assegurar uma educação de qualidade social para todos os munícipes.

Ao entrecruzar as leituras teóricas com os acontecimentos do campo empírico, é possível afirmar que a participação de toda comunidade escolar nas diferentes tomadas de decisão da escola é um aspeto relevante para a constituição da gestão democrática. A participação precisa ser uma prática constante da comunidade escolar nas ações pedagógicas e administrativas da unidade escolar, assim como na escolha dos gestores, na perspectiva de efetivar a gestão democrático-participativa na arena escolar.

A pesquisa permitiu realizar outras interpretações sobre a gestão democrática e compreender os elementos dificultadores para efetivação da gestão escolar democrática no 
cotidiano municipal: ausência de normas claras no ordenamento jurídico pátrio, comutação de leis e discursos para atender os interesses daqueles que detém o poder, pouco interesse dos governantes para instituir a gestão escolar democrática e limitadas organizações escolares para reivindicar a efetivação das leis. Subverter tais entraves exige mudança de concepção político-filosófica dos governantes e da sociedade montessantense, órgãos colegiados atuantes e, sobretudo, aspiração política para democratizar a gestão das escolas e a educação pública.

Diante das discussões realizadas sobre um tema tão amplo, a expectativa é que os resultados contribuam para o entendimento de que o processo eletivo é o método de escolha de gestores escolares que dialoga com os anseios da comunidade escolar e que contribui para descentralizar o poder, propiciando maior participação de todos os atores que compõem a escola. Outrossim, o desejo é que este debate - que está longe de ser finalizado - provoque o poder público e a comunidade escolar a pensar e a construir mecanismos que reduzam o distanciado entre o promulgado e a prática.

\section{REFERÊNCIAS}

ALVES, F. C. Mapeamento das políticas de escolha de diretores da escola e de avaliação na rede pública das capitais brasileiras. Rev. Bras. Est. pedag., Brasília (DF), v. 90, n. 224, p. 71-86, jan./abr. 2009. Disponível em:

http://rbep.inep.gov.br/ojs3/index.php/rbep/article/view/920/667. Acesso em: 17 jan. 2021.

BRASIL. Constituição (1988). Constituição da República Federativa do Brasil. Brasília, DF: Senado, 1988.

BRASIL. Diretrizes Curriculares Nacionais Gerais da Educação Básica. Brasília, DF: MEC/SEB, 2013.

BRASIL. Plano Nacional de Educação 2014-2024: Lei n. 13.005, de 25 de junho de 2014, que aprova o Plano Nacional de Educação (PNE) e dá outras providências. Brasília, DF: Câmara dos Deputados, 2014.

BRASIL. Lei de Diretrizes e Bases da Educação Nacional. Lei no 9.394/1996. 3. ed. Brasília: Senado Federal, 2019.

ESQUINSANI, R. S. S. Contribuições ao debate sobre gestão democrática da educação: foco em legislações municipais sul-rio-grandenses. Rev. bras. Estud. pedagog., Brasília (DF), v. 97, n. 247, p. 490-505, set./dez. 2016. Disponível em: https://www.scielo.br/pdf/rbeped/ v97n247/2176-6681-rbeped-97-247-00490.pdf. Acesso em: 16 jan. 2021.

GIL, A. C. Métodos e técnicas de pesquisa social. 6. ed. São Paulo, SP: Atlas, 2008.

KOZINETS, R. V. Netnografia: realizando pesquisa etnográfica online. Porto Alegre, RS: Penso, 2014. 
LIBÂNEO, J. C. Organização e gestão da escola: teoria e prática. 5. ed. Goiânia, GO: Alternativa, 2004.

LIMA, A. B. Adeus à gestão (escolar) democrática. Revista Arquivo Brasileiro de Educação, Belo Horizonte (MG), v. 1, n. 1, p. 27-50, 2013. Disponível em: http://periodicos.pucminas.br/index.php/arquivobrasileiroeducacao/article/view/P.23187344.2013v1n1p27. Acesso em: 16 jan. 2021.

LIMA, L. C. Por que é tão difícil democratizar a gestão da escola pública? Educar em Revista, Curitiba (PR), Brasil, v. 34, n. 68, p. 15-28, mar./abr. 2018. Disponível em: https://www.scielo.br/pdf/er/v34n68/0104-4060-er-34-68-15.pdf. Acesso em: 10 jan. 2021.

LÜCK, H. Dimensões de gestão escolar e suas competências. Curitiba, PR: Positivo, 2009.

LÜDKE, M.; ANDRÉ, M.E. D. A. Pesquisa em educação: abordagens qualitativas. São Paulo, SP: EPU, 1986.

MONTE SANTO. Decreto n. 404, de 7 de novembro de 2018. Regulamenta o procedimento das Eleições Diretas para Escolha e Nomeação para o Exercício da Função de Diretor e Vicediretor das escolas da rede Pública Municipal de Ensino para o triênio 2019/2021 e dá outras providências. Monte Santo, BA, 2018. Disponível em:

https://montesanto.ba.io.org.br/diarioOficial/download/519/1098/0. Acesso em 15 jan. 2021.

MONTE SANTO. Lei de n. 001/2016. Dispõe sobre o Plano de Cargos, Carreira, remuneração e Funções Públicas dos Servidores Efetivos da Educação Básica Pública Municipal de Monte Santo e dá outras providências. Monte Santo, BA, 2016. Disponível em: http://doem.org.br/ba/montesanto?dt=2016-03-16. Acesso em: 12 jan. 2021.

MONTE SANTO. Lei n. 003/2021. Dispõe sobre a alteração da Lei Municipal nº 16/2013 que dispõe sobre o Estatuto do Magistério Público do Município de Monte Santo, alterada pelas Leis n ${ }^{0}$ 025/2017 e 088/2020, e dá outras providências. Monte Santo, BA, 2021.

Disponível em: https://doem.org.br/ba/montesanto?dt=2021-02-16. Acesso em: 06 jun. 2021.

MONTE SANTO. Lei n. 025/2017, de 28 de dezembro de 2017. Altera a Lei Municipal $\mathbf{n}^{\mathbf{0}}$ 16/2013, de 22 de agosto de 2013, que dispõe sobre o Estatuto do Magistério Público do Município e a Lei Municipal no 001/2016, de 14 de março de 2016, que dispõe sobre o Plano de Cargos, Carreira, Remuneração e Funções Públicas dos Servidores Efetivos da Educação Básica Pública Municipal, e dá outras providências. Monte Santo, BA, 2017. Disponível em: https://montesanto.ba.io.org.br/diarioOficial/download/519/689/0. Acesso em: 15 jan. 2021.

MONTE SANTO. Lei n. 05, de 25 de junho de 2015. Aprova o Plano Municipal de Educação (PME) do Município de Monte Santo em consonância com a Lei no 13.005/2014 que trata do Plano Nacional de Educação (PNE), e dá outras providências. Monte Santo, BA, 2015. Disponível em: https://doem.org.br/ba/montesanto?dt=2015-06-26. Acesso em: $18 \mathrm{de}$ jan. 2021.

MONTE SANTO. Lei n. 088/2020. Dispõe sobre a alteração da Lei Municipal nº 16/2013 que dispõe sobre o Estatuto do Magistério Público do Município de Monte Santo e dá outras 
providências, alterada pela Lei $\mathrm{n}^{\circ}$ 025/2017. Monte Santo, BA, 2020. Disponível em: https://montesanto.ba.io.org.br/diarioOficial/download/519/2137/0. Acesso em: 12 jan. 2021.

MONTE SANTO. Lei n. 16/2013. Dispõe sobre o Estatuto do Magistério Público do Município de Monte Santo e dá outras providências. Monte Santo, BA, 2013. Disponível em: http://doem.org.br/ba/montesanto?dt=2014-11-06. Acesso em: 12 jan. 2021.

MONTE SANTO. Lei Orgânica do Município de Monte Santo. Monte Santo, BA: Câmara Municipal, 2017. Disponível em: http://doem.org.br/ba/montesanto?dt=2017-01-03. Acesso em: 12 jan. 2021.

MORAES, R. Uma tempestade de luz: a compreensão possibilitada pela análise textual discursiva. Ciência \& Educação, v. 9, n. 2, p. 191-211, 2003. Disponível em: https://www.scielo.br/pdf/ciedu/v9n2/04.pdf. Acesso em: 13 jan. 2021.

OLIVEIRA, I. C.; VASQUES-MENEZES, I. Revisão de literatura: o conceito de gestão escolar. Cadernos de Pesquisa, v. 48, n. 169, p. 876-900, jul./set. 2018. Disponível em: https://www.scielo.br/pdf/cp/v48n 169/1980-5314-cp-48-169-876.pdf. Acesso em: 16 jan. 2021.

PARO, V. H. Crítica da estrutura da escola. São Paulo, SP: Cortez, 2011.

PARO, V. H. Gestão democrática da escola pública. 4. ed. São Paulo, SP: Cortez, 2016.

SANTOS, S. M. M.; CASTRO, S. B. D. Gestão Escolar em Feira de Santana: análise dos textos oficiais. Educação \& Realidade, Porto Alegre (RS), v. 45, n. 1, e-92062, 2020. Disponível em: https://www.scielo.br/pdf/edreal/v45n1/2175-6236-edreal-45-01-e92062.pdf. Acesso em: 15 jan. 2021.

SOUZA, Â. R. Explorando e construindo um conceito de gestão escolar democrática.

Educação em Revista, Belo Horizonte (MG), v. 25, n. 3, p. 123-140, dez. 2009. Disponível em: https://www.scielo.br/pdf/edur/v25n3/07.pdf. Acesso em: 15 jan. 2021. 


\section{Como referenciar este artigo}

OLIVEIRA, S. S. Gestão escolar democrática: entre o promulgado e a prática. Revista on line de Política e Gestão Educacional, Araraquara, v. 25, n. 3, p. 2147-2162, set./dez. 2021. e-ISSN:1519-9029. DOI: https://doi.org/10.22633/rpge.v25i3.14744

Submetido em: 11/02/2021

Revisões requeridas em: 28/05/2021

Aprovado em: 15/06/2021

Publicado em: 08/12/2021

RPGE- Revista on line de Política e Gestão Educacional, Araraquara, v. 25, n. 3, p. 2147-2162, set./dez. 2021. e-ISSN: 1519-9029 